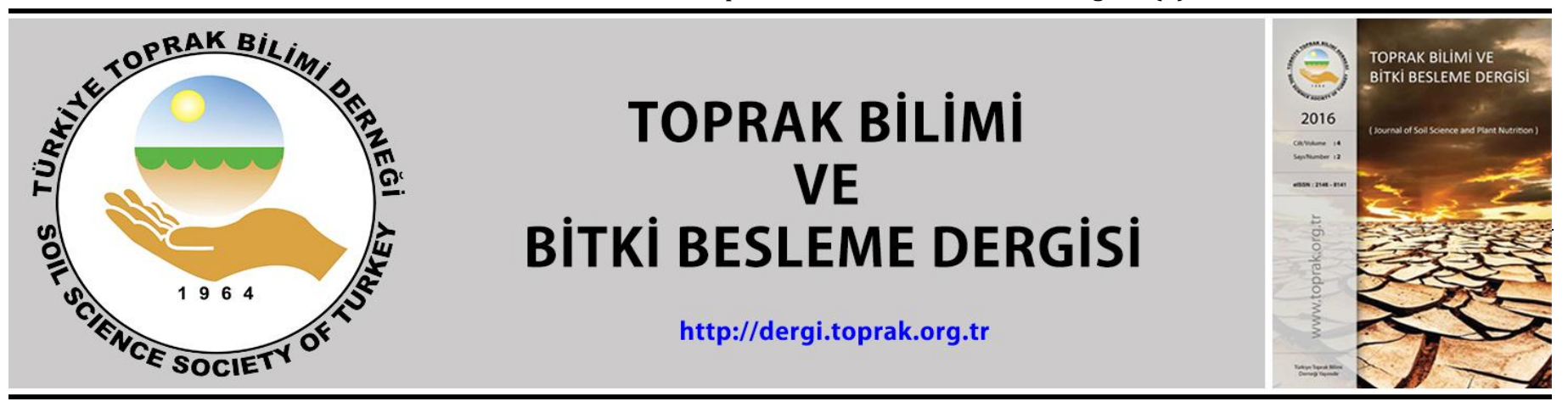

\title{
Şeker pancarı yapraklarında azot durumunun spektral diskriminant analizi ile belirlenmesi
}

\section{Mert Dedeoğlu ${ }^{1, *}$, Levent Başayiğit ${ }^{2}$, Murat Erişoğlu ${ }^{3}$}

${ }^{1}$ Selçuk Üniversitesi, Ziraat Fakültesi, Toprak Bilimi ve Bitki Besleme Bölümü, Konya

2 Isparta Uygulamalı Bilimler Ün., Tarım Bilimleri ve Teknolojileri Fak., Toprak Bilimi ve Bitki Besleme Bölümü, Isparta ${ }^{3}$ Necmettin Erbakan Üniversitesi, Fen Fakültesi, İstatistik Bölümü, Konya

\begin{abstract}
Özet
$\mathrm{Bu}$ çalışmada ülkemiz için stratejik öneme sahip şekerpancarı bitkisinin yaprak \%N sınıflarının belirlenmesine yönelik hiperspektral yansımalar kullanılarak bir yöntem geliştirilmesi amaçlanmıştır. Bu amaçla 3 farklı vejetasyon evresini temsil eden noksan, yeter ve fazla N içerikli Hoagland sölüsyonları (Hoagland ve Arnon, 1938) ile 72 deneme bitkisi kontrollü sera şartlarında, perlit ortamında yetiştirilmiş, spektroradyometre ile 400-1000 nm arası spektral ölçümler ve \%N tayini için yaprak örneklemeleri yapılmıştır. Şekerpancarı yapraklarında farklı dönem ve dozlarla ilişkili dalgaboylarının belirlenmesinde stepwise çoklu regresyon analizi uygulanmıș ve belirlenen 48 farklı dalgaboyu yansıma değerinden temel bileșenler analizi ile toplam varyansa en yüksek katkıyı sağlayan 5 dalgaboyu (474-517-652-721-961 nm) model için seçilmiştir. Belirlenen dalgaboyları kullanılarak kodlanan Karesel Diskriminant Analiz (KDA) modeli 72 bitkiyi \%92 doğrulukla gerçek sınıflarına $\left(\mathrm{N}_{\mathrm{Noksan}} ; \% 92, \mathrm{~N}_{\text {Yeter; }} \% 88\right.$ ve $\mathrm{N}_{\text {Fazla; }} \% 96$ ) atamıștır. Modelin validasyonu için kullanılan 36 test verisinin $\% 89$ doğrulukla \%N sınıflarına $\left(\mathrm{N}_{\mathrm{Noksan}} \%{ }_{0} 91, \mathrm{~N}_{\text {Yeter; }} \% 85\right.$ ve $\mathrm{N}_{\text {Fazla; }}$ \%92) ayrımı yapılmış ve seçilen dalgaboylarından olan spektral yansımaların KDA modeli ile farkı vejetasyon dönemleri için şekerpancarı azotlu gübreleme ihtiyacının tespitinde kullanılabilir olduğu belirlenmiștir. Araștırma sonucu spektral veriler ile bitki besin durumunun belirlenmesine yönelik çalıșmalara diskriminant modellerinin kullanımı için umut verici bulgular elde edilmiș ve KDA modelinin farklı bitki türü ve besin elementleri için kurgulanacak deneme desenlerinde kullanılarak geliştirilmesi önerilmiştir. Anahtar Kelimeler: Azot, hiperspektral yansıma, karesel diskriminant, spektroradyometre.
\end{abstract}

\section{Determination of sugar beet nitrogen status by spectral discriminant analysis}

\begin{abstract}
In this study, it is aimed to develop a method by using hyperspectral reflections to determine the leaf N\% status of sugar beet which is strategically important for our country. For this purpose, 72 experimental plants were grown in controlled greenhouse conditions and perlite environment with Hoagland solutions with deficient and excess $\mathrm{N}$ content representing 3 different vegetation stages, then spectral measurements were taken between $400-1000 \mathrm{~nm}$ by spectroradiometer and leaf samples were collected for determination of $\mathrm{N} \%$. Stepwise multiple regression analysis was applied to determine the wavelengths associated with different periods and $\mathrm{N}$ doses in sugar beet leaves and 5 wavelengths (474-517-652-721-961 nm) were selected for the highest contribution to the total variance from the 48 different wavelength reflection values. The Quadratic Discriminant Analysis (QDA) model, which was coded using determined wavelengths, assigned 72 plants to their real classes ( $\mathrm{N}_{\text {Deficient; }} ; 92 \%$, N $\mathrm{N}_{\text {Suficient }} ; 88 \%$ and $\mathrm{N}_{\text {Excess; }} ; 96 \%$ ) with $92 \%$ accuracy. The 36 test data used for validation of the model were discriminated into $89 \% \mathrm{~N}$ classes ( $\mathrm{N}_{\text {Deficient; }} 91 \%$, Nsufficient; 85\% and Nexcess; 92\%) with 89\% accuracy, and it was determined that using QDA model with spectral reflections of the selected wavelengths can be used to detect for sugar beet $\mathrm{N}$ demand during different vegetation stages. As a result of the research has been obtained encouraging findings for the use of discriminant models to the studies on determination of plant nutritional status by spectral data and we was proposed that the QDA model should be developed using different plant species and nutrients on the experimental designs.
\end{abstract}

Keywords: Hyperspectral reflectance, nitrogen, quadratic discriminant, spectroradiometer

(c) 2019 Türkiye Toprak Bilimi Derneği. Her Hakkı Saklıdır

\section{Giriş}

Ülkemiz için şekerpancarı, gıda güvenliğinin sağlanması başta olmak üzere ithal kamış şekerine bağlı kalmaksızın yurt içi tüketimin, yurt içinde üretilen şeker ile karşılanması, katma değer sağlaması, istihdam sunması ve köyden göçü engelleyici özelliği nedeniyle stratejik bir üründür. Ülkemizde yaklaşı 500 bin

\footnotetext{
* Sorumlu yazar:

Tel. 05304160006

E-posta
}

Geliş Tarihi

Kabul Tarihi
20 Eylül 2019

7 Kasim 2019
e-ISSN : 2146-8141

DOI : $10.33409 /$ tbbbd.668890 
çiftçi ailesi pancar tarımı ile geçimini sağlarken, şeker fabrikalarında daimî ve mevsimlik olarak yaklaşık 30.000 kiși istihdam edilmektedir. Türkiye'de yaklaşık 330.000 ha alanda pancar ekimi yapılmakta ve ortalama 6.10 ton verim elde edilmektedir. Bu istatistiklere en büyük katkıyı Konya ili sağlamaktadır. Konya ili, 173 köy de 306.240 da şeker pancarı ekimi yapılan arazisi ile 54 il arasında en büyük alana sahip olup ortalama 6.88 ton/da verim elde edilmektedir. (Anonim, 2018). Tüm bitkisel yetiştiriciliklerde olduğu gibi şeker pancarı verim ve kalitesi ile mutlak gerekli besin elementlerinin yetiştirme ortamındaki yeterli ve dengeli oranları paralellik göstermektedir. Pancar yetiştiriciliği için de karbon, hidrojen ve oksijenden sonra en önemli element azottur (Gezgin ve ark., 1999). Azot başta klorofil pigmenti olmak üzere proteinler, nükleik asitler, amino asitler ve hücre bileşenlerinin yapısında, bitki gelişim sürecini düzenleyen ve katalize eden çeşitli enzimatiklerden, bitki parazit ve hastalıklarına karşı direnç arttırıcı kimyasal bileşenlerin oluşumuna kadar pek çok metabolik işlevde anahtar rol oynamaktadır (Sinfield ve ark., 2010). Ancak bitki verim ve kalitesi ile doğrudan ilişkili olan azotun toprak içeriğindeki miktarına dayanılarak nitelikli ve bol ürün alınması pancar yetiştiriciliği için olası değildir. Nitekim farklı dozda azotlu gübre uygulamalarının şekerpancarının verim ve kalitesine etkilerinin araştırılması sonucu azot noksanlığında kök sistemi gelişiminin, verimin ve şeker sentezinin azaldığı belirtilmiştir (Gezgin ve ark., 2001). Bu nedenle vejetasyon dönemi içerisinde belli aralıklarla ve yeterli dozlarda azotlu gübrelerin toprağa uygulanması gerekmektedir. Azotlu gübrelerde azot nitrat $\left(\mathrm{NO}_{3}^{-}\right)$, amonyum $\left(\mathrm{NH}_{4}{ }^{+}\right)$ve üre $\left(\mathrm{CH}_{4} \mathrm{~N}_{2} \mathrm{O}\right)$ formunda bulunup ülkemizde ve dünyada en fazla tüketilen gübrelerdir (Eyüpoğlu, 2002). Ancak toprağa sonradan ilave edilen tüm kimyasal maddelerde olduğu gibi azotlu gübrelerinde hem yetiştirici maliyeti hem de çevresel faktörler açısından bilimsel esaslara dayanarak kontrollü bir şekilde uygulanması gerekmektedir (Karaçal ve Tüfenkçi, 2010). Azotun litosfer ve atmosfer içerisinde tüm canlı yaşantısına etkilerine karşın bitkiler için vazgeçilmez bir besin elementi olması, etkin azotlu gübre uygulamalarının bitkiler için optimum seviyede, çevre için asgari düzeyde yapılmasını zorunlu kılmaktadır. Bu nedenlerden ötürü bitkilerde azot seviyesinin belirlenmesine yönelik pratik, hızlı, tahrip edici olmayan ve çevre dostu metotlar araştırılmaktadır (Demotes ve ark., 2008). $\mathrm{Bu}$ amaçla klorofil ve polifenoller gibi bazı yaprak pigmentlerinin elektromanyetik spektrumun görünür yakın kızılötesi dalga boylarındaki yansıma özelliklerini kullanan tarımsal amaçlı uzaktan algılama çalışmaları yürütülmekte (Vigneau ve ark., 2011) ve geleneksel olarak uygulanmakta olan laboratuvar analizlerine bir alternatif olduğu belirtilmektedir (Kostrzewski ve ark., 2002; Wójtowicz ve ark., 2016; Başayigit ve ark, 2017). Bitki azot noksanlığına dayalı stres koşullarının erken dönemde belirlenebilirliğine yönelik bu yaklaşım ilgi görmektedir (Maimaitiyiming ve ark, 2017). Bitki stresi, biyotik veya abiyotik faktörlerin bitkilerde ayrı ayrı ya da birlikte olumsuz şekilde fizyolojik ve metabolik değişimlere yol açmasıdır. Stres faktörleri büyümeyi ve gelişmeyi gerileterek üründe nitelik ve niceliğin yitmesine, daha ileri aşamalarda bitkinin ve bitki organlarının yaşantısını yitirmesine neden olmaktadır (Kacar ve ark., 2002). Bitki besin elementi stresi de önemli abiyotik etmenlerden biri olan ve uzun yıllardır araştırmacılar tarafından çalışılan bir konudur (Ayala-Silva ve Beyl, 2005; Başayigit ve ark, 2017). Besin elementi noksanlığı veya toksitesi durumunda özellikle bitki yapraklarında arazide yorumlanabilen klorozlar meydana gelmekte ancak klorozun algılanması kişiye göre değişmekte ve klorozun kaynağı kişinin tecrübesine göre tespit edilebilmektedir. Bu tür morfolojik gözlemler yetiştirici bazında sayısal verilere dayandırılmadan gübre uygulamaları ile giderilmeye çalışılmakta, bu durumda gereksiz gübre kullanımı kaynaklı toprak tuzlulaşması, su kirliliği, bitkilerde madde yığılımı ve ekonomik kayıplar meydana getirmektedir (Karaçal ve Tüfenkçi, 2010). Direk ya da dolaylı yoldan tüm canlı yaşantısını olumsuz etkileyen bu sebeplerden dolayı besin elementi stres koşullarının bitki üzerinde klorozlar meydana gelmeden erken teşhis edilebilirliği uzaktan algılama çalışmalarının da önemli bir dalı olmuştur (Jackson, 1986; Bagheri ve ark., 2012; Maimaitiyiming ve ark, 2017). Yapılan çalışmalar bitkilerin kimyasal kompozisyonları ile bitki yeşil aksamından farklı dalga boylarında elde edilen spektral yansımaların (spektral imza) matematiksel olarak ilişkilendirilmesine dayanmaktadır (Li ve ark., 2008; Başayigit ve ark, 2017). Yersel ölçüm teknikleri yeşil aksamın belli bir yükseklikten (canopy) ya da direk bitki dokusu ile temas edilerek hiperspektral algılama yeteneğine sahip, elle taşınabilen spektroradyometreler veya dijital kameralar kullanılarak yansıma ölçümlerinin yapılmasını kapsamaktadır (Jackson, 1986). Bu tekniklerden elde edilen yansıma değerleri ile bitki besin elementi içerikleri arasında pozitif yönlü yüksek korelasyon olduğu bilinmektedir (Ayala-Silva ve Beyl, 2005; Wójtowicz ve ark., 2016). Nitekim azotlu gübrelerle toprağa uygulanan faklı miktarlardaki azotun şeker pancarı bitkisi tarafından alınımı yersel hiperspektral kamera ile araştırılmış ve hiperspektral görüntüler ile bireysel olarak değerlendirilen şeker pancarı bitkilerinin yaşlı yapraklarında düşük, genç yapraklarında yüksek azot içeriğine sahip olduğu PLS regresyon analizi kullanılarak (RMSECV $=1.72$ G/KG; PLS-R $\left.{ }^{2}=0.86\right)$ modellenmiştir. Aynı zamanda hiperspektral kameralar ile bitkide azot dağılımının haritalanabileceği bildirilmiştir (Jay ve ark., 2014). Benzer olarak Çin de kışlık 
buğday bitkisinin azot seviyesi ile hiperspektral yansıma ölçümlerinden hesaplanan RVI (red vegetation index) değerleri arasında $r^{2}=0.79$ oranında ilișki belirlenmiș ve kışlık buğdayın azot durumunun tahmininde RVI' nin kullanılabilir olduğu bildirilmiştir (Li ve ark., 2008). Buğday bitkisine ait hiperspektral yansıma ölçümlerinin 40 farklı vejetasyon indislemesi sonucu elde edilen değerlerin $\mathrm{N}$ konsantrasyonlarını farklı oranda tahmin edebildiğini, özellikle kızıl-kenar (red edge) dalga boyu yansımaları kullanan indislerin yüksek doğrulukta $\left(r^{2}=0.87\right)$ tahminler yaptığı rapor edilmiştir (He ve ark., 2013). Yapılan araştırmalar ve elde edilen bulgular incelendiğinde yersel hiperspektral teknikler ile bitkilerin azot durumlarının tahminine yönelik indis ve modelleme çalışmaları güvenilir sonuçlar vermektedir (Fitzgerald ve ark., 2010; Eitel ve ark., 2011) Ancak araștırmalarda besin elementi içerik konsantrasyonlarının belirlenmesinde ürüne özgü modeller geliştirilmesi için farklı bitki desenlerinde yersel hiperspektral ölçüm teknikleri uygulanarak daha fazla çalışmalar yürütülmesi gerekliliği ortaya konulmaktadır (Haboudane ve ark., 2008; Fitzgerald ve ark., 2010; Mee ve ark., 2017).

$\mathrm{Bu}$ araştırma ile Konya ovası ve ülkemiz için stratejik ve sosyolojik öneme sahip şeker pancarı (Beta vulgaris) bitkisinin optimum gelişiminde anahtar rol oynayan ve en yüksek kimyasal gübre girdisine sahip Azot $(\mathrm{N})$ besin elementinin șeker pancarı yapraklarında noksan-yeter-fazla sınıflarının hiperspektral yansıma ölçümleri kullanılarak erken dönemde belirlenmesine yönelik bir metot çalışması yürütülmüştür.

\section{Materyal ve Yöntem}

\section{Sera denemesi}

Çalışma şeker pancarı yapraklarında noksan, yeter ve fazla seviyede azot beslenmesinin kontrol edilebilir olması için perlit kullanılarak, 3 farklı seviyede $\mathrm{N}$ içeren Hogland (Hogland ve Arnon, 1938) besin solüsyonları ile $260 \mathrm{~m}^{2}$ büyüklüğünde S.Ü. Ziraat Fakültesi Toprak Bilimi ve Bitki Besleme Bölümü Bilgisayar Kontrollü Serasında saksı denemesi kurularak yürütülmüştür. Topraksız kültürde su ve besin içeriği en kolay kontrol edilebilen materyal olan perlitin kimyasal özellikleri açsından besin maddesi içermediği ve bu sayede kontaminasyonların engellenerek planlanan besin elementi içeriklerinin besin solüsyonu uygulamaları ile yapraklarda oluşturulabildiği bilinmektedir (Alpaslan ve ark., 2005). Bu nedenle şeker pancarı yetiştiriciliği perlit ortamında yapılmıştır. Şeker pancarı yapraklarında faklı N sınıflarının oluşturulabilmesi için uygulanacak besin solüsyonlarının $\mathrm{N}$ konsantrasyonları ön deneme çalışması ile belirlenmiş ve $\mathrm{N}_{\text {NOKSAN }}$ için 10 ppm, N NETER için 60 ppm ve $\mathrm{N}_{\mathrm{FAZLA}}$ için 200 ppm saf azot uygulamaları ile Jones ve ark. (1991) göre şeker pancarı yapraklarında kritik \%N seviyelerini temsil edecek aralıklar ( $<\% 4$ yetersiz, \%4-6 yeterli, > \%6 fazla) elde edilmiștir. Saksılara besin solüsyonu uygulamaları sulama aralıkları belirlenerek verilmiştir. Bu amaçla bitkilerin su ihtiyacı her tekerrürde bir adet saksıya yerleștirilen saksı tipi tansiyometre ile takip edilmiştir. Şeker pancarı için sulama sınırı 60 cbar olarak belirtilmiş olup (Draycott ve Christenson, 2003), saksı su potansiyeli 60 cbar değerine geldiğinde, saksılara drenaj deliklerinden akış başlayana kadar Hogland solüsyonu uygulanmıştır. Bu sayede bitki yetiştirme ortamında devamlı mutlak gerekli besin elementleri sağlanmış olup aynı zamanda değişen azot dozu uygulamaları yapılmıştır. Çalışma şeker pancarı bitkisinin çimlenme- çıkış, vejetatif gelişme ve kök şişirme (Faberio ve ark., 2003), dönemlerini kapsayacak şekilde $3 \%$ uygulaması x 24 bitki $=72$ saksıda yürütülmüştür.

\section{Hiperspektral ölçümler ve yaprak örneklemesi}

Farklı dozda N uygulaması yapılan şeker pancarı bitkilerinin yapraklarında vejetasyon dönemleri boyunca 15 gün arayla 8 kez taşınabilir ASD FieldSpec HandHeld (Analytical Spectral Devices Inc., Boulder, CO, USA) spektroradyometre cihazı ve aktif sensörlü bitki aparatları (Plant Probe) kullanılarak 400-1000 nm dalgaboyları arasında ve her saksıdan 3 tekerrürlü olmak üzere yansıma ölçümleri yapılmıştır. Ölçümlerde yaprakların uç kısımlarından, yaprak ayasının (lamina) ışık kaynağını görecek şekilde damar aralarına yerleştirilmesi ile spektral yansımalar toplanmıştır. Cihazın kalibrasyonunda 10-15 dakikada bir defa olmak üzere, ölçüm başlangıcında "Dark Current Correction" işlemi yapılmış ve beyaz referans olan baryum sülfattan $\left(\mathrm{BaSO}_{4}\right)$ imal edilmiş spektralon kullanılmıştır (Huang ve ark., 2017). Spektral ölçümler bir deneme bloğuna ait 3 saksıda 3 tekerrürlü olarak yapılmış olup, yansıma değerleri kaydedilen yapraklar alüminyum örnek poşetlerine koyulup toplam azot analizleri için soğutucu dolaplar içerisinde laboratuvara götürülmüștür. Yaprak örneklemesi yapılan pancar bitkileri deneme bloğundan ayrılmıştır. Böylece örnekleme esnasında bitki dokusuna verilen zararın blok uygulamalarına etkisi giderilmiş ve deneme sürecince yeterli sayıda yaprak örneğinde çalışılmıştır. Nitekim 15 gün arayla 3 tekerrürlü yapılan örneklemeler ile her parselden 24 saksı 3'er azaltılarak 21-18-15-12-9-6-3-0 saksıya kadar 8 seferde deneme çalışmaları tamamlanmıştır. Çalışma ile $3 \mathrm{~N}$ uygulaması $\left(\mathrm{N}_{\text {noksan }}-\mathrm{N}_{\text {yeter }}-\mathrm{N}_{\text {fazla }}\right) \mathrm{X}$ her bloğa ait 3 saksı 
X her saksıdan 3 yaprak örneği X 8 ölçüm üç vejetasyon dönemi için = 216 yansıma ölçümü ve yaprak örneklemesi yapılmıştır.

\section{Laboratuvar analizleri}

Kontrollü sera şartlarında örneklemesi yapılan şeker pancarı yapraklarının toplam \%N içerikleri LECO CN2000 (LECO Corp.) cihazında Dumas (Wright ve Bailey, 2001) metoduyla örneklemenin yapıldığı gün beklenilmeden belirlenmiştir (Çizelge 1).

Çizelge 1. Şeker pancarı yaprak \% N içeriklerine ait tanıtıcı istatistikler

\begin{tabular}{lccccccc}
\hline \%N dozu & Ortalama & Min. & Maks. & Std.Sapma & Varyans & CoefVar & Skewness \\
\hline Noksan & 2.49 & 2.14 & 2.86 & 0.25 & 0.065 & 10.23 & 0.24 \\
Yeter & 5.49 & 5.26 & 5.78 & 0.17 & 0.028 & 3.06 & 0.56 \\
Fazla & 7.70 & 7.01 & 8.19 & 0.27 & 0.074 & 3.53 & -0.50 \\
\hline
\end{tabular}

Laboratuvar analizi sonucu deneme alanı örneklerinin $\mathrm{N}$ için \%2.14-\%8.19 arasında 3 farklı azot sınıfını temsil edecek șekilde dağılım gösterdiği belirlenmiștir. Yaprak örneklerinin \%N içeriklerinin tekerrür ortalamaları alınmıș ve 72 uygulamaya ait yansıma değerleri ve \%N içerikleri istatistik analizler ve model uygulamaları için vejetasyon dönemlerine göre şeker pancarı \%N sınıflarına kategorize edilerek kaydedilmiştir.

\section{Vejetasyon dönemleri ve \%N içeriklerine göre dalga boyu seçimi}

Çalışmada 72 gözlemden (n) her bir gözlem için 400-1000 nm dalgaboyu arasında 601 yansıma değişkeni (p) barındıran eğitim veri seti oluşturulmuş ve çoklu karşılaştırma testi olan stepwise çoklu linear regresyon analiz yöntemiyle (Curran ve ark., 2001), üç farklı vejetasyon dönemi için regresyon modelleri farklı değişken (dalgaboyu) kombinasyonları kullanılarak en az 4 en fazla 6 bant ile $\mathrm{r}^{2}=0.70-1.00$ katsayılı oluşturulmuştur (Çizelge 2). Nitekim yapılan çalışmalarda bitkilerin \%N içeriklerinin spektral yansıma değerleri ile ilişkisinin belirlenmesinde regresyon katsayısı $\left(\mathrm{r}^{2}\right) 0.70$ ve üzeri değerleri "kuvvetli" olarak nitelemektedir (Haboudane ve ark., 2002; Rodriguez ve ark., 2006; Wu ve ark, 2008; Fitzgerald ve ark., 2010; Feng ve ark., 2014; Huang ve ark., 2017).

Çizelge 2. Üç dönem ve üç \%N sınıfı ile dalgaboyu yansıma oranlarının regresyon ilişkisi ve modelleri

\begin{tabular}{|c|c|c|c|}
\hline $\mathrm{N}$ dozu & & & $\mathrm{R}^{2}$ \\
\hline $\begin{array}{c}\text { Noks } \\
\text { an }\end{array}$ & $\begin{array}{c}4 \\
\mathrm{Ba} \\
\mathrm{nt}\end{array}$ & $N=7.095+(-62.08 \times 796 \mathrm{~nm})+(65.65 \times 860 \mathrm{~nm})+(-5.92 \times 937 \mathrm{~nm})+(-2.59 \times 754 \mathrm{~nm})$ & $\begin{array}{c}1.0 \\
0\end{array}$ \\
\hline Yeter & $\begin{array}{c}4 \\
\mathrm{Ba} \\
\text { nt }\end{array}$ & $N=4.212+(-9.51 \times 721 \mathrm{~nm})+(10.12 \times 995 \mathrm{~nm})+(-2.79 \times 986 \mathrm{~nm}+(0.328 \times 980 \mathrm{~nm})$ & $\begin{array}{c}1.0 \\
0\end{array}$ \\
\hline Fazla & $\begin{array}{c}4 \\
\text { Ba } \\
\text { nt }\end{array}$ & $N=19.578+(2.52 \times 717 \mathrm{~nm})+(-75.5 \times 981 \mathrm{~nm})+(72.3 \times 1000 \mathrm{~nm})+(-13.6 \times 978 \mathrm{~nm})$ & $\begin{array}{c}0.9 \\
9\end{array}$ \\
\hline N Dozu & & & $\mathrm{R}^{2}$ \\
\hline $\begin{array}{c}\text { Noks } \\
\text { an }\end{array}$ & $\begin{array}{c}6 \\
\mathrm{Ba} \\
\mathrm{nt}\end{array}$ & $\begin{aligned} N=-0.469+(20.16 \times 993 \mathrm{~nm})+(-11.29 \times 937 \mathrm{~nm})+(-3.27 \times 978 \mathrm{~nm}+(9.27 \times 986 \mathrm{~nm})+(-9.1 \\
+(-1.58 \times 829 \mathrm{~nm})\end{aligned}$ & $\begin{array}{l}9.11 .0970 \mathrm{~nm}) \\
0\end{array}$ \\
\hline Yeter & $\begin{array}{c}6 \\
\mathrm{Ba} \\
\mathrm{nt}\end{array}$ & $\begin{aligned} N=-0.2087+ & (19.5252 \times 405 \mathrm{~nm})+(36.41 \times 909 \mathrm{~nm})+(-24.885 \times 832 \mathrm{~nm})+(-2.4032 \times 950 \mathrm{~nm} \\
& +(-4.996 \times 892 \mathrm{~nm})+(0.633 \times 906 \mathrm{~nm})\end{aligned}$ & $\begin{array}{c}m 1.0 \\
0\end{array}$ \\
\hline Fazla & $\begin{array}{c}6 \\
\mathrm{Ba} \\
\mathrm{nt}\end{array}$ & $\begin{array}{c}N=7.4463+(-27.53 \times 403 \mathrm{~nm})+(58.944 \times 429 \mathrm{~nm})+(-137.87 \times 457 \mathrm{~nm})+(134.35 \times 454 \mathrm{~nm}) \\
+(-51.44 \times 474 \mathrm{~nm})+(20.48 \times 605 \mathrm{~nm})\end{array}$ & $\begin{array}{c}0.9 \\
8\end{array}$ \\
\hline N Dozu & & & $\mathrm{R}^{2}$ \\
\hline $\begin{array}{c}\text { Noks } \\
\text { an }\end{array}$ & $\begin{array}{c}6 \\
\text { Ba } \\
\text { nt }\end{array}$ & $\begin{array}{c}N=-5.56028+(-34.7728 \times 412 \mathrm{n}+(48.1473 \times 408 \mathrm{~nm})+(22.1665 \times 745 \mathrm{~nm})+(-13.9691 \times 100 \\
+(-6.0041 \times 422 \mathrm{~nm})+(-0.8730 \times 941 \mathrm{~nm})\end{array}$ & $\begin{array}{l}000.0 m) \\
0\end{array}$ \\
\hline
\end{tabular}




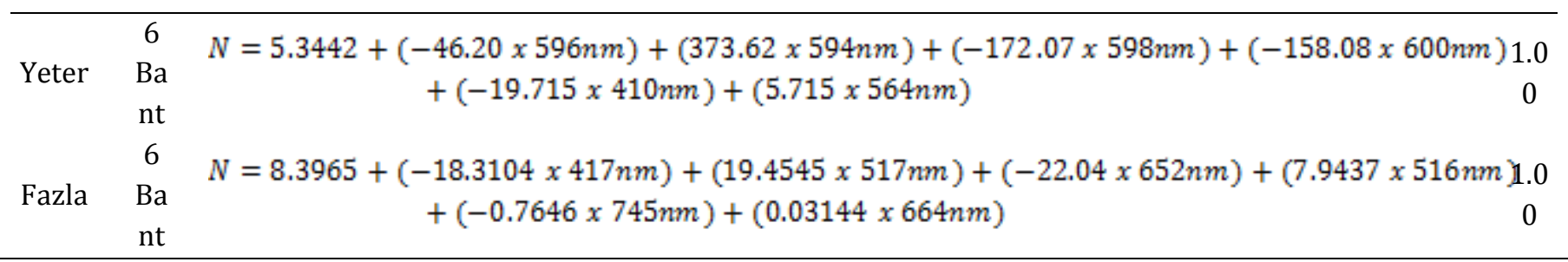

Çalışmada dalgaboyu yansıma oranları ve \%N içerikleri arasında farklı vejetasyon dönemlerinde belirlenen regresyonel ilişkiye ait modellerde kullanılan toplam 48 dalgaboyu ve yansıma değerlerinde, daha küçük bağımsız değişkenler seti oluşturulması için temel bileşenler analizi (TBA) uygulanmıştır (Zhao ve ark., 2000). Öyleki çok değişkenli modelleme çalışmaları en az değişken ile en fazla faydayı sağlamaya yönelik çıkarımlar için kullanılmaktadır (Erisoglu ve ark., 2012). Bu nedenle TBA ile toplam varyansa en yüksek katkıyı sağlayan 5 dalgaboyu (474-517-652-721-961 $\mathrm{nm}$ ) belirlenmiş ve diskriminant modelinde fonksiyonlanmıştır.

\section{Karesel diskriminant analizi uygulaması ve model geliştirme}

Üç vejetasyon dönemi ve üç farklı \%N sınıfı ile ilişkilendirilen dalgaboyları ve yansımaları, tüm dönemleri ve $\% \mathrm{~N}$ dozlarını kapsayan 72 eğitim verisine "Karesel Discriminant Analizi (KDA)" ile Matlab 2016 (MathWorks, 2007) istatistik programında kodlanarak uygulanmıştır. Lineer diskriminant analizinde her grup için ortak varyans- kovaryans matrisi ile çok değişkenli normal dağılım varsayımı yapılırken, KDA analizinde gruplara ait varyans- kovaryans matrislerinin eșit olma zorunluluğu yoktur ve her grubun kendi varyans- kovaryans matrisi ile çok değişkenli normal dağılıma sahip olduğu varsayılır (Hastie ve ark., 2009; James ve ark., 2013). KDA'nde her grup ortalama vektörü $\boldsymbol{\mu}_{\boldsymbol{k}}$ ve varyans-kovaryans matrisi $\boldsymbol{\Sigma}_{\boldsymbol{k}}$ ile çok değişkenli normal dağılıma sahip olduğunda; $k=1,2, \ldots, G$ olmak üzere KDA'nde sınıflama kuralı

$$
\bar{C}_{K D A}(\boldsymbol{x})=\underset{k}{\operatorname{argmax}} P\left(G=k \mid \boldsymbol{x}=\boldsymbol{x}^{*}\right)
$$

eşitliği ile ifade edilir. Burada;

$$
\begin{aligned}
& \log \left\{P\left(G=k \mid \boldsymbol{x}=\boldsymbol{x}^{*}\right)\right\} \propto-\frac{1}{2}\left(\boldsymbol{x}^{*}-\boldsymbol{\mu}_{\boldsymbol{k}}\right)^{\prime} \boldsymbol{\Sigma}_{\boldsymbol{k}}^{-1}\left(\boldsymbol{x}^{*}-\boldsymbol{\mu}_{\boldsymbol{k}}\right)+\log \left(\pi_{k}\right)+d \\
& =-\frac{1}{2} \boldsymbol{x}^{8^{\prime}} \boldsymbol{\Sigma}_{\boldsymbol{k}}^{-1} \boldsymbol{x}^{*}+\boldsymbol{x}^{8^{\prime}} \boldsymbol{\Sigma}_{\boldsymbol{k}}^{-1} \boldsymbol{\mu}_{\boldsymbol{k}}-\frac{1}{2} \boldsymbol{\mu}_{\boldsymbol{k}} \boldsymbol{\Sigma}_{\boldsymbol{k}}^{-1} \boldsymbol{\mu}_{\boldsymbol{k}}+\log \left(\pi_{k}\right)+d
\end{aligned}
$$

eşitliği ile ifade edilir. Eşitlikte yer alan $\pi_{k}$ gösterimi $k_{*}$ gruba ait önsel olasılığı gösterir. Eşitlikte yer alan $d$ sabit terimi gösterir ve her grup için aynı olduğundan dolayı karesel diskriminant fonksiyonu

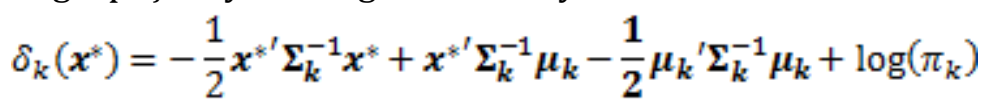

ile gösterilir.

\section{Model validasyonu}

Seçilen 5 dalgaboyu ile 72 birimlik veri seti eğitim verisi olarak kabul edilmiş ve ilgili veri seti kullanılarak KDA modeli geliştirilmiştir. KDA modelinin başarısını incelemek için farklı \%N düzeylerini temsil eden toplam $36\left(\mathrm{~N}_{\mathrm{NOKSAN}}: 11, \mathrm{~N}_{\text {YETER }}: 12, \mathrm{~N}_{\mathrm{FAZLA}}: 13\right)$ birimden oluşan test verisi oluşturulmuştur. Diskriminant modelinin test verilerini ait oldukları sınıflara \%51 ve üzerinde doğru atama yapması durumunda modelin güvenilir olduğu ifade edilmektedir (Reynolds, 2015).

\section{Bulgular ve Tartışma}

Șeker pancarı yapraklarında gerçekleștirilen ölçüm ve örnekleme işlemleri sonucu yaprak örneklerine ait $\% \mathrm{~N}$ içerikleri çalışmanın amacına uygun bir şekilde 3 farklı sınıfta homojen bir dağılım göstermektedir. Bu sayede üretilen model şeker pancarı için tüm azot eşiklerini temsil etmektedir. Nitekim, spektral yansımalar ile bitki besin elementi durumlarının tahmini için ilgili besin elementinin değișen dozlarının bitkilerde oluşturulması gerekmektedir (Basayigit ve ark., 2015).

Üç farklı döneme ait ortalama \%N içerikleri ve spektral eğrileri ile deneme bitkilerinin morfolojileri Şekil 1,2,3'de sunulmuştur.

Burada 3 farklı \%N sınıflarına ait yaprak örneklerinin ortalama spektral eğrileri incelendiğinde; N'un değișen seviyelerine bağlı olarak 440 - $750 \mathrm{~nm}$ arası yansımalarda farklılık meydana geldiği belirlenmiștir. Bu durum artan $\mathrm{N}$ seviyelerinin klorofilaz enzim aktivite hızını arttırması ve bu sayede klorofil miktarının da 
artması sonucu yansımalarda azalma olduğunu göstermektedir (Zhang ve ark., 2018), ve klorofil $a$ - $b$ miktarı ile 425, 455 and $485 \mathrm{~nm}$ de en yüksek absorpsiyon yapan carotenoids pigmenti arasında doğru orantı olduğu belirtilmektedir (Merzlyak ve ark., 2003). Yapılan araștırmalarda azot bitki besin elementi eksikliğinde yansıma değerlerinde çok yüksek artışlar meydana geldiği ve noksanlığın derecesine göre yansımalardaki artışın \%90’lara ulaştığı belirtilmektedir (Basayigit ve ark., 2009; Fernàndez-Martínez ve ark., 2017). Bu sonuçlar farklı N uygulamalarının yansıma eğrilerinde istatistiksel olarak anlamlı farklılıklar oluşturduğunu göstermiş ve şeker pancarı \%N sınıflarının belirlenmesinde KDA analizi için kullanılabilir bulunmuştur. Analiz için farklı vejetasyon dönemlerinde 3 farklı \%N sınıflarına ait deneme bitkilerinden elde edilen 474517-652-721-961 nm dalgaboyu yansıma değerleri eğitim verisi olarak seçilmiştir. Eğitim verisinde her sınıfta eşit sayıda gözlem olduğundan dolayı, her bir sınıf için önsel olasılık değerleri $\pi_{1}=\pi_{2}=\pi_{3}=1 / 3$ olarak alınmıştır. Her sınıfa ait ortalama vektörü ve varyans-kovaryans matrisleri Çizelge 3'de sunulmuştur.

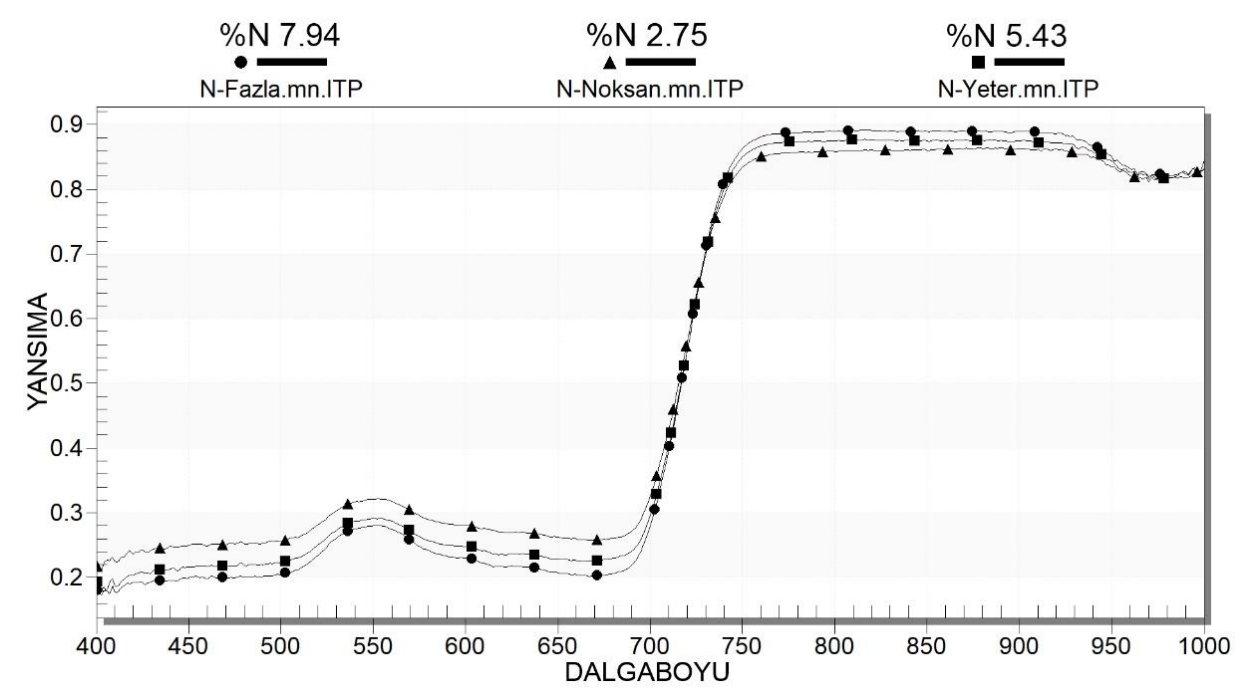

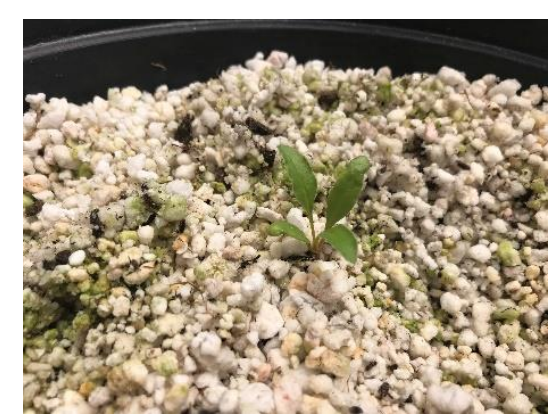

Noksan

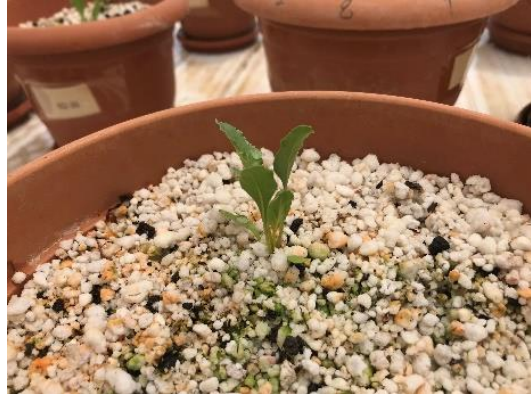

Yeter

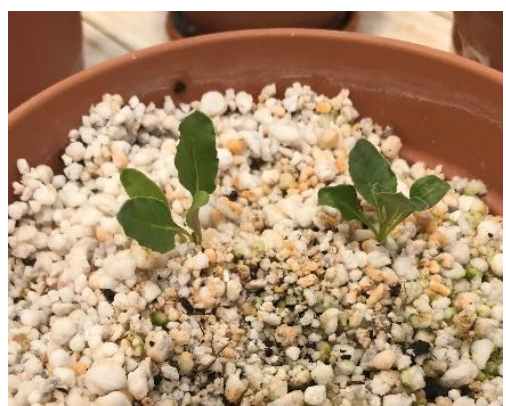

Fazla

Şekil 1. Çimlenme ve çıkış dönemine ait spektral eğriler ve deneme bitkileri 


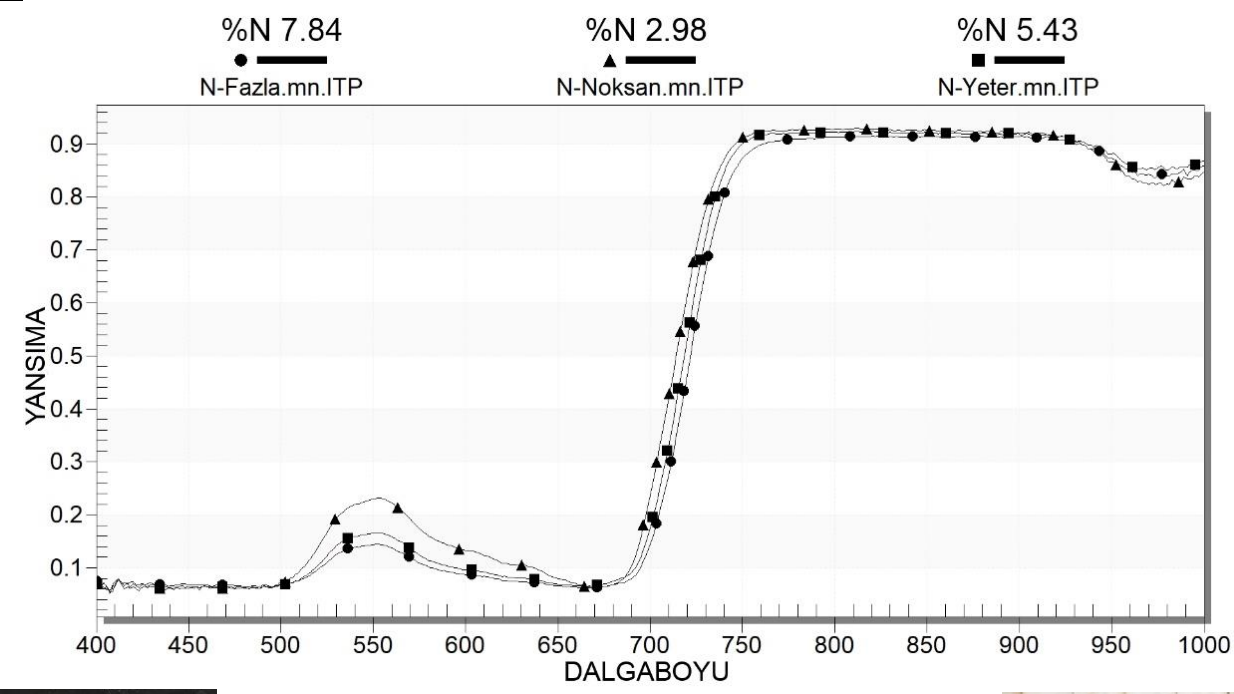

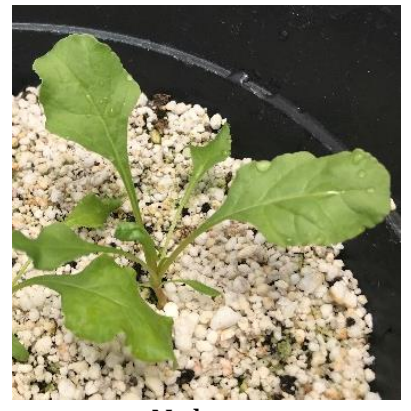

Noksan

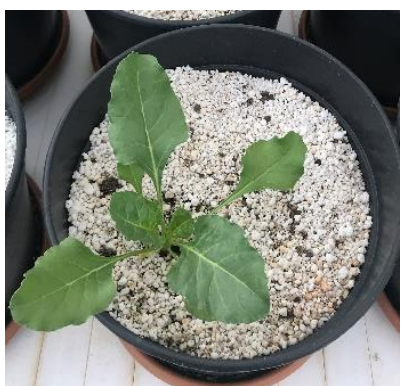

Yeter

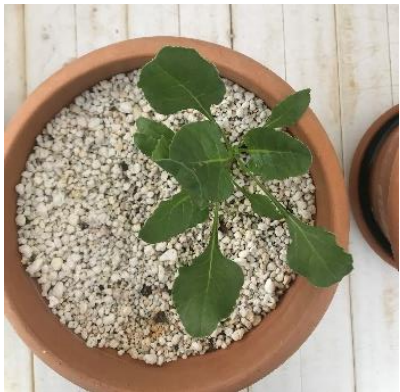

Fazla

Şekil 2. Vejetatif gelişme dönemine ait spektral eğriler ve deneme bitkileri

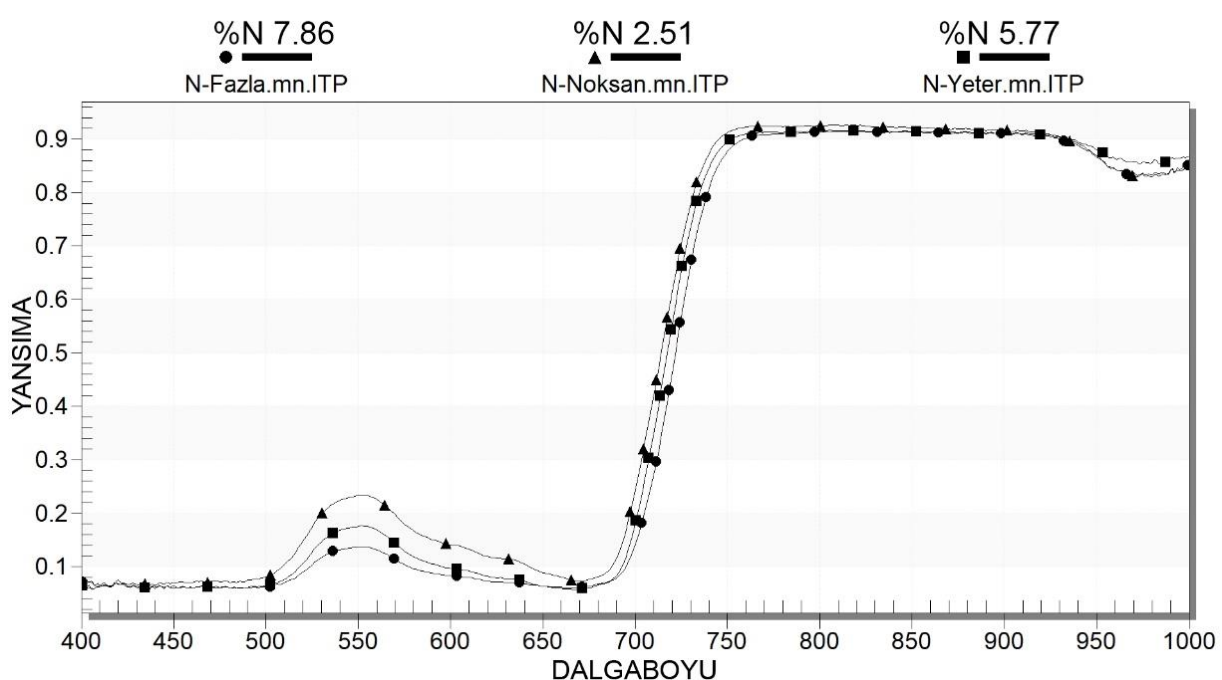

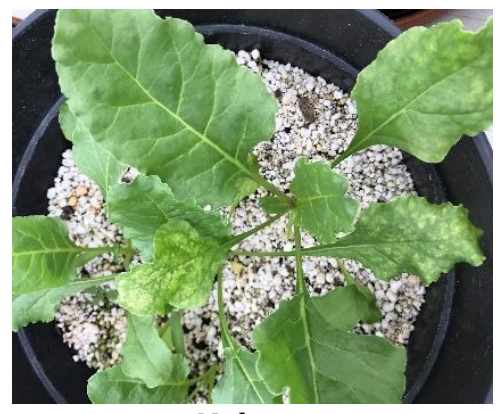

Noksan

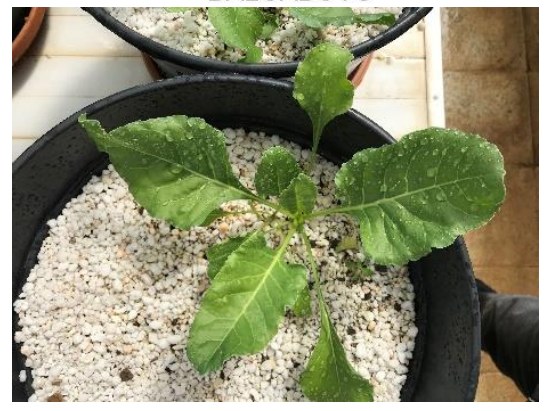

Yeter

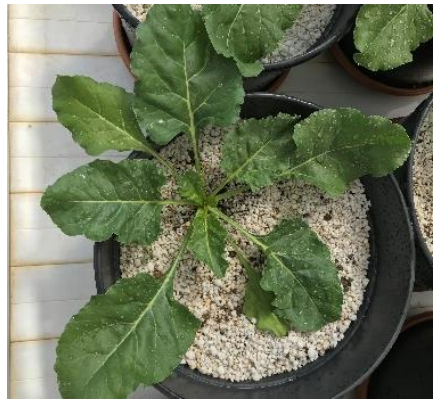

Fazla 
Şekil 3. Kök şişirme dönemine ait spektral eğriler ve deneme bitkileri

Çizelge 3. Çok değişkenli karesel diskriminant analizinde parametre tahminleri

\begin{tabular}{|c|c|c|c|c|c|}
\hline \multirow{2}{*}{ Parametreler } & \multicolumn{5}{|c|}{ Dalgaboyu } \\
\hline & 474 & 517 & 652 & 721 & 961 \\
\hline \multirow[t]{3}{*}{$\widehat{\mu}_{1}$} & 0.11258 & 0.15713 & 0.12817 & 0.59021 & 0.84038 \\
\hline & 0.00904 & 0.00829 & 0.00883 & 0.00186 & 0.00120 \\
\hline & 0.00829 & 0.00769 & 0.00815 & 0.00201 & 0.00115 \\
\hline \multirow[t]{3}{*}{$\overline{\mathbf{\Sigma}}_{1}$} & 0.00883 & 0.00815 & 0.00866 & 0.00197 & 0.00119 \\
\hline & 0.00186 & 0.00201 & 0.00197 & 0.00157 & 0.00048 \\
\hline & 0.00120 & 0.00115 & 0.00119 & 0.00048 & 0.00037 \\
\hline \multirow[t]{3}{*}{$\widehat{\mu}_{2}$} & 0.07750 & 0.10533 & 0.08538 & 0.51096 & 0.84542 \\
\hline & 0.00165 & 0.00157 & 0.00166 & 0.00026 & -0.00025 \\
\hline & 0.00157 & 0.00151 & 0.00159 & 0.00027 & -0.00026 \\
\hline \multirow[t]{3}{*}{$\widetilde{\Sigma}_{2}$} & 0.00166 & 0.00159 & 0.00169 & 0.00027 & -0.00028 \\
\hline & 0.00026 & 0.00027 & 0.00027 & 0.00022 & 0.00007 \\
\hline & -0.00025 & -0.00026 & -0.00028 & 0.00007 & 0.00038 \\
\hline \multirow[t]{3}{*}{$\widehat{\mu}_{3}$} & 0.09267 & 0.11254 & 0.09746 & 0.47092 & 0.84375 \\
\hline & 0.00598 & 0.00599 & 0.00616 & 0.00340 & 0.00020 \\
\hline & 0.00599 & 0.00600 & 0.00617 & 0.00343 & 0.00019 \\
\hline \multirow[t]{3}{*}{$\bar{\Sigma}_{3}$} & 0.00616 & 0.00617 & 0.00635 & 0.00352 & 0.00019 \\
\hline & 0.00340 & 0.00343 & 0.00352 & 0.00209 & 0.00013 \\
\hline & 0.00020 & 0.00019 & 0.00019 & 0.00013 & 0.00024 \\
\hline
\end{tabular}

Deneme bitkilerinden $400-1000 \mathrm{~nm}$ arasında 72 gözlemden elde edilen tüm yansımaların test verisi olarak geliştirilen 3 farklı modele fonksiyonlanması sonucu özellik vektörü $X$ 'in (farklı azot seviyelerine ait yansıma oranları) mümkün olan 3 gruba (\%N sınıfları) $\mathrm{N}_{\text {Noksan }} ; 92 \%, \mathrm{~N}_{\text {Yeter }} ; 88 \%$ ve $\mathrm{N}_{\text {Fazla; }}$; $96 \%$ doğrulukla atamasının yapıldığı belirlenmiş (Çizelge 4), ve modelin genel doğru sınıflandırma olasılığı \%92 olduğundan Reynolds (2015)'e göre güvenilir kabul edilmiştir.

Geliştirilen model eğitim verisinin \%N sınıflarını yüksek doğruluk ile tahmin etmiş ve sonraki aşamada model validasyonu için 36 birimlik test verisinde denenmiştir. Test verisinde Çizelge 3'de verilen model parametre tahmin değerleri ile gerçekleştirilen diskriminant sonucu elde edilen sınıf arama matrisi Çizelge 5 'de sunulmuştur.

Çizelge 4. Eğitim verilerinin çok değişkenli normal olasılık fonksiyonu sonucu sınıf atama matrisi

\begin{tabular}{|c|c|c|c|c|c|}
\hline & & & \multicolumn{3}{|c|}{ Gerçek } \\
\hline & & & Noksan & Yeter & Fazla \\
\hline \multirow{6}{*}{ Tahmin } & Noksan & & 22 & 0 & 0 \\
\hline & Yeter & & 2 & 21 & 1 \\
\hline & Fazla & & 0 & 3 & 23 \\
\hline & & Toplam & 24 & 24 & 24 \\
\hline & & ${ }^{*} D S O$ & $\% 92$ & $\% 88$ & $\% 96$ \\
\hline & & Genel DSO & & $\% 92$ & \\
\hline
\end{tabular}

*DSO: Doğru sınıflandırma olasılı̆̆ 1

Çizelge 5. Test örneklerine ait yansımaların çok değişkenli normal olasılık fonksiyonu sonucu sınıf atama matrisi

\begin{tabular}{|c|c|c|c|c|c|}
\hline \multirow{8}{*}{ Tahmin } & & & \multicolumn{3}{|c|}{ Gerçek } \\
\hline & & & Noksan & Yeter & Fazla \\
\hline & Noksan & & 10 & 0 & 0 \\
\hline & Yeter & & 1 & 11 & 1 \\
\hline & Fazla & & 0 & 2 & 11 \\
\hline & & Toplam & 11 & 13 & 12 \\
\hline & & DSO & $\% 91$ & $\% 85$ & $\% 92$ \\
\hline & & Genel DSO & & $\% 89$ & \\
\hline
\end{tabular}


Geliştirilen model ile özellik vektörü X 'in (farklı sınıflara ait yansıma oranları) mümkün olan G gruptan (3 $\% \mathrm{~N}$ sınıfı) birisine \%89 doğrulukla atamasının yapılabildiği belirlenmiștir. Yapılan çalıșmalarda bitkilerin $\% \mathrm{~N}$ içeriklerinin spektral yansıma değerleri ile tahmininde doğruluk katsayısı \%70 ve üzeri değerler "kuvvetli" olarak nitelemekte ve üretilen modeller için "güvenilir" olarak belirtmektedir (Fitzgerald ve ark., 2010; Feng ve ark., 2014). Çalışma sonucu elde edilen bulgulara göre KDA modelinin spektral verilerin sınıflamasına yönelik çalışmalardaki başarısı (Ju ve ark., 2003; Çalış and Erol, 2012), yersel hiperspektral ölçümler ile de sağlanmıştır. Diskriminant modelleri birçok alanda rasgelelik içeren doğal olayların farklı özellikleri hakkında toplanan ölçüm değerlerine istatistiksel olarak model oluşturmada matematiksel bir yaklaşım sağlamakta (Manolakis ve ark., 2001), ve spektral verilerin analizinde belirli bir spektral veriden her bir spektrumun ayrıştırabilir olmasından dolayı kullanışlı bir yöntem olarak değerlendirilmekte ve kullanılmaktadır (Gillis ve ark, 2008; Çalış ve Erol, 2012; Deng ve ark., 2015). Ancak bitkilerde besin elementi seviyelerinin kategorizasyonu ve spektral teknikler ile tahmin edilmesinde diskriminant yaklaşımlarının kullanımlarına yönelik literatür eksikliği vardır. Nitekim bu alanda yürütülen birçok çalışmada özellikle stepwise multiple linear regression (Wang ve ark., 2017), partial least squares regression (Jain ve ark., 2007), mutivariate linear regression (Krishna ve ark., 2019), yaklaşımlarının kullanımları yaygındır. Ancak çoklu regresyon analizleri sonucu üretilen modellerin tahminleri geliştirildikleri parsel ve bitki türlerinde (kendi içerisinde) yüksek doğruluk katsayılı $\left(r^{2}\right)$ sonuçlar veriyor iken, farklı arazilerde bulunan aynı bitki türlerinde tahmin güçlerinin önemli ölçüde düştüğü belirtilmektedir (Huang ve ark., 2017; Başayigit ve ark., 2017). Bu çalışmada kullanılan diskriminant yaklaşımı ile doğrudan olarak \%N içeriklerinin tahmin edilmesinden daha çok şeker pancarı için kritik \% $\mathrm{N}$ sınıflarına atama yapılması test verilerinde de yüksek doğrulukla sonuçlar vermiştir. Benzer şekilde Foster ve ark., (2016), arazi koşullarında distkriminat analizi kullanarak yaprak spektumlarından farklı $\mathrm{N}$ uygulamalarının $\mathrm{r}^{2}=0.94-0.97$ belirleme katsayısı ile izlenebildiği belirtilmiştir. Aynı zamanda KDA modelinin geliştirilmesinde kullanılan dalgaboylarının şeker pancarının 3 farklı vejetasyon dönemi için ilişkili olmasının modelin başarısını arttırdığı düşünülmektedir. Nitekim spektral yansımalar ile bitkilerin fenolojik durumları arasında anlamlı bir yapı oluşturabilmek için, ölçümleme tarihlerinin bitkilerin gelişim dönemlerini temsil edecek zaman dilimleri içerisinde gerçekleştirilmesi gerektiği belirtilmektedir (Morisette ve ark., 2006). Araştırma bulguları göstermiştir ki hiperspektral yansıma verileri kullanılarak geliştirilen KDA modeli ile $\mathrm{N}$ besin elementinin bitkilerde ki eşik aralıkları yüksek doğrulukla belirlenebilmektedir.

\section{Sonuç}

Çalışma ile şekerpancarı yapraklarında \%N sınıflarının belirlenmesinde bitki dokusunu tahrip etmeyen, ekonomik, hızlı, çevre dostu ve pratik bir model geliştirilmiş, başarısı test edilmiştir. Çalışma sonucu el tipi spektroradyometre ile ölçülen ve Karesel Diskriminant analizi ile modellenen hiperspektral yansıma verilerinin şeker pancarı vejetasyon dönemleri boyunca $\% \mathrm{~N}$ sinıflarının belirlenmesi ve izlenmesinde yüksek doğrulukta kullanılabilir olduğu belirlenmiştir. Geçmişten günümüze spektral teknikler ile özellikle N elementinin belirlenmesine yönelik pek çok araştırma farklı bitki türlerinde yapılmış ve benzer şekilde görünür-yakınkızıötesi (VNIR) dalgaboyu yansıma değişimleri \%N içeriği ile ilişkilendirilmiştir. Bu çalışmada farklı olarak doğrudan şeker pancarı yapraklarında \%N içeriklerinin tahmin edilmesi yerine daha geniş bir dağılım gösteren \%N sınıflarına yüksek doğrulukla atamalar yapılmış ve seçilen dalgaboylarından olan spektral yansımaların KDA modeli ile farkı vejetasyon dönemleri için şekerpancarı azotlu gübreleme ihtiyacının tespitinde kullanılabilir olduğu belirlenmiștir. Bu sayede hiperspektral veriler ile bitki besin statüsünün belirlenmesine yönelik çalışmalara faklı bir yaklaşım sunulmuştur. Aynı zamanda çalışmada modelleme amacıyla kullanılan Karesel Diskriminant analizinin başarılı ve güçlü bir matematiksel yaklaşım olduğu sonucuna varılmıştır. Bu yönüyle ileriki çalışmalara farklı bir pencere açmış ve hiperspektral uzaktan algılama ile farklı besin elementi içeriklerinin sınıf atamalarında kullanılabilir olduğu önerilmiş ve geleneksel yöntemlere alternatif olması yönüyle umut verici sonuçlar elde edilmiştir.

\section{Teşekkür}

Bu çalışma Selçuk Üniversitesi Bilimsel Araştırma Projeleri Koordinatörlüğü (BAP) tarafından desteklenen "Geniş Bant Görünür Yakın Kızılötesi (VNIR) Yansıma Spektroskopisi İle Pancar Bitkisinin Farklı Vejetasyon Dönemlerinde Kritik Azot İçeriği Sınıflarının Belirlenmesi” isimli ve "18401103” nolu proje çalışmasının bir bölümünden hazırlanmıștır. BAP birimine desteğinden ötürü teșekkürlerimizi sunarız.

\section{Kaynaklar}

Alpaslan M, Güneș A, İnal A, 2005. Deneme tekniği. Ankara Üniversitesi Ziraat Fakültesi Yayınları, (1501): 455. 
Anonim, 2018. http://www.tarim.gov.tr/Konular/Bitkisel-Uretim/Bitki-Besleme-ve-Tarimsal-Teknolojiler/BitkiBesleme-Istatistikleri.

Ayala-Silva T, Beyl CA, 2005. Changes in spectral reflectance of wheat leaves in response to specific macronutrient deficiency. Advances in Space Research 35(2): 305-317.

Bagheri N, Ahmadi H, Alavipanah S, Omid M 2012. Soil-line vegetation indices for corn nitrogen content prediction. International Agrophysics 26(2): 103-108.

Basayigit L, Albayrak S, Senol H, 2009. Analysis of VNIR reflectance for prediction of macro and micro nutrient and chlorophyll contents in apple trees (Malus communis). Asian Journal of Chemistry 21(2): 1302.

Basayigit L, Dedeoglu M, Akgül H, 2015. The prediction of iron contents in orchards using VNIR spectroscopy. Turkish Journal of Agriculture and Forestry 39(1): 123-134.

Başayigit L, Dedeoğlu M, Akgül H, Uçgun K, Altındal M, 2017. Investigation of N deficiency in cherry trees using visible and near-infrared spectra part of the spectrum in field condition. Spectroscopy and Spectral Analysis. 37(1): 293298.

Curran PJ, Dungan JL, Peterson DL, 2001. Estimating the foliar biochemical concentration of leaves with reflectance spectrometry: Testing the kokaly and clark methodologies. Remote Sensing of Environment. 76(3): 349-359.

Çalış N, Erol H, 2012. A new per-field classification method using mixture discriminant analysis. Journal of Applied Statistic. 39(10): 2129-2140.

Demotes-Mainard S, Boumaza R, Meyer S, Cerovic ZG, 2008. Indicators of nitrogen status for ornamental woody plants based on optical measurements of leaf epidermal polyphenol and chlorophyll contents. Scientia Horticulturae. 115(4): 377-385.

Deng S, Xu Y, Li X, He Y, 2015. An infinite Gaussian mixture model with its application in hyperspectral unmixing. Expert Systems with Applications. 42(4): 1987-1997.

Draycott AP, Christenson DR, 2003. Nutrients for sugar beet production: Soil-plant relationships. Cabi.

Eitel JU, Vierling LA, Litvak ME, Long DS, Schulthess U, Ager AA, Stoscheck L, 2011. Broadband, red-edge information from satellites improves early stress detection in a New Mexico conifer woodland. Remote Sensing of Environment. 115(12): 3640-3646.

Erisoglu U, Erisoglu M, Erol H, 2012. Mixture model approach to the analysis of heterogeneous survival data. Pakistan Journal of Statistics 28(1): 115-130.

Eyüpoğlu F, 2002. Türkiye gübre gereksinimi tüketimi ve geleceği. Toprak ve Gübre Araştırma Enst. İşlt. Müd. Ankara.

Faberio C, Martin de Santa Olalla F, Lopez R, Dominguez A, 2003. Production and quality of the sugar beet cultivated under contrelled deficit irrigation conditions in a semi-arid climate. Agricultural Water Management. 62: 215227.

Feng W, Guo BB, Wang ZJ, He L, Song X, Wang YH, 2014. Measuring leaf nitrogen concentration in winter wheat using double-peak spectral reflection remote sensing data. Field Crops Research. 159: 43-52.

Fernàndez-Martínez J, Joffre R, Zacchini M, Fernández-Marín B, García-Plazaola JI, Fleck I, 2017. Near-infrared reflectance spectroscopy allows rapid and simultaneous evaluation of chloroplast pigments and antioxidants, carbon isotope discrimination and nitrogen content in Populus spp. leaves. Forest Ecology and Management. 399: 227-234.

Fitzgerald G, Rodriguez D, O'Leary G, 2010. Measuring and predicting canopy nitrogen nutrition in wheat using a spectral index-The canopy chlorophyll content index (CCCI). Field Crops Research. 116(3): 318-324.

Foster AJ, Kakani VG, Ge J, Gregory M, Mosali J, 2016. Discriminant analysis of nitrogen treatments in switchgrass and high biomass sorghum using leaf and canopy-scale reflectance spectroscopy. IJR. 37(10): 2252-2279.

Gezgin S, Dursun N, Hamurcu M, Ayaslı Y, 1999. Konya ovasında şeker pancarı bitkisinde beslenme sorunlarının toprak ve bitki analizleri ile belirlenmesi. Konya Pancar Ekicileri Kooperatifi Yayını, Konya.

Gezgin S, Hamurcu M, Dursun N, 2001. Konya ovasında şeker pancarının azot ve fosfor ihtiyacının belirlenmesi. S. $\ddot{U}$. Ziraat Fakültesi Dergisi. 15(25): 119-131.

Gillis D, Bowles J, Ientilucci EJ, Messinger DW, 2008 A generalized linear mixing model for hyperspectral imagery. In Algorithms and Technologies for Multispectral, Hyperspectral, and Ultraspectral Imagery XIV, 2008 (Vol. 6966 , pp. 69661B): International Society for Optics and Photonics.

Haboudane D, Miller JR, Tremblay N, Zarco-Tejada PJ, Dextraze L, 2002. Integrated narrow-band vegetation indices for prediction of crop chlorophyll content for application to precision agriculture. Remote Sensing of Environment. 81(2): 416-426.

Haboudane D, Tremblay N, Miller JR, Vigneault P, 2008. Remote estimation of crop chlorophyll content using spectral indices derived from hyperspectral data. IEEE Transactions on Geoscience and Remote Sensing 46: 423-437.

Hastie T, Tibshirani R, Friedman J, Hastie T, Friedman J, Tibshirani R, 2009. The elements of statistical learning. Springer.

He L, Zhang HY, Zhang YS, Song X, Feng W, Kang GZ, Guo TC, 2016. Estimating canopy leaf nitrogen concentration in winter wheat based on multi-angular hyperspectral remote sensing. European Journal of Agronomy. 73: 170-185.

Hoagland DR, Arnon DI, 1938. The water culture method for growing plants without soil. Circ. Calif. Agr. Exp. Sta. 347: 461. 
Huang S, Miao Y, Yuan F, Gnyp M, Yao Y, Cao Q Bareth G, 2017. Potential of RapidEye and WorldView-2 satellite data for improving rice nitrogen status monitoring at different growth stages. Remote Sensing. 9(3): 227.

Jackson RD, 1986. Remote sensing of biotic and abiotic plant stress. Annual Review of Phytopathology. 24:265-286.

Jain N, Ray SS, Singh J, Panigrahy S, 2007. Use of hyperspectral data to assess the effects of different nitrogen applications on a potato crop. Precision Agriculture, 8(4-5): 225-239.

James G, Witten D, Hastie T, Tibshirani R, 2013. An introduction to statistical learning. Springer, New York. 112:18.

Jay S, Hadoux X, Gorretta N, Rabatel G, 2014. Potential of hyperspectral imagery for nitrogen content retrieval in sugar beet leaves. Proc. int. conf. ag. eng., AgEng2014, Zurich, The European Society of Agricultural Engineers (EurAgEng), 2014:8.

Jones JR, Wolf B, Mills HA, 1991. Plant analysis handbook. Micro Macro Publishing Inc.

Ju J, Kolaczyk ED, Gopal S, 2003. Gaussian mixture discriminant analysis and sub-pixel land cover characterization in remote sensing. Remote Sensing of Environment. 84(4):550-560.

Kacar B, Katkat AV, Oztürk S, 2002. Bitki fizyolojisi. Uludag Ü. Güclendirme Vakfi Yayini. No: 198 Vipas A.S. Yayin No: 74, ISBN: 975-564-133-5 Bursa.

Karaçal İ, Tüfenkçi Ş, 2010. Bitki beslemede yeni yaklaşımlar ve gübre-çevre ilişkisi. ZMO. 2010.

Kostrzewski M, Waller P, Guertin P, Haberland J, Colaizzi P, Barnes E, Thompson T, Clarke T, Riley E, Choi C, 2002. Ground-based remote sensing of water and nitrogen stress. Trans. Am. Soc. Assoc. Exec. 46: 29-38.

Krishna G, Sahoo RN, Singh P, Bajpai V, Patra H, Kumar S, 2019. Comparison of various modelling approaches for water deficit stress monitoring in rice crop through hyperspectral remote sensing. Agricultural Water Management. 213: 231-244.

Li F, Gnyp ML, Jia LL, Miao YX, Yu ZH, Koppe W, Bareth G, Chen XP, Zhang FS, 2008. Estimating N status of winter wheat using a handheld spectrometer in the North China Plain. Field Crops Research. 106: 77-85.

Maimaitiyiming M, Ghulam A, Bozzolo A, Wilkins JL, Kwasniewski MT, 2017. Early detection of plant physiological responses to different levels of water stress using reflectance spectroscopy. Remote Sensing. 9(7): 745.

Manolakis D, Siracusa C, Shaw G, 2001. Hyperspectral subpixel target detection using the linear mixing model. IEEE Transactions on Geoscience and Remote Sensing. 39(7): 1392-1409.

MathWorks, I. (2007). Instrument control toolbox 2: user's guide. The MathWorks Inc.

Mee CY, Siva KB, Ahmad HMH, 2017. Detecting and monitoring plant nutrient stress using remote sensing approaches: A review. Asian Journal of Plant Sciences. 16: 1-8.

Merzlyak MN, Solovchenko AE, Gitelson AA, 2003. Reflectance spectral features and non-destructive estimation of chlorophyll, carotenoid and anthocyanin content in apple fruit. Postharvest Biology and Technology. 27(2): 197211.

Morisette JT, Baret F, Privette JL, Myneni RB, Nickeson JE, Garrigues S, Kalacska M, 2006. Validation of global moderateresolution LAI products: A framework proposed within the CEOS land product validation subgroup. IEEE Transactions on Geoscience and Remote Sensing. 44(7): 1804-1817.

Reynolds D, 2015. Gaussian mixture models. Encyclopedia of biometrics. 827-832.

Rodriguez D, Fitzgerald GJ, Belford R, Christensen LK, 2006. Detection of nitrogen deficiency in wheat from spectral reflectance indices and basic crop eco-physiological concepts. Australian Journal of Agricultural Research. 57(7): 781-789.

Sinfield JV, Fagerman D, Colic 0, 2010. Evaluation of sensing technologies for on-the-go detection of macro-nutrients in cultivated soils. Computers and Electronics in Agriculture. 70(1): 1-18.

Vigneau N, Ecarnot M, Rabatel G, Roumet P, 2011. Potential of field hyperspectral imaging as a non destructive method to assess leaf nitrogen content in Wheat. Field Crops Research. 122(1): 25-31.

Wang Z, Skidmore AK, Wang T, Darvishzadeh R, Heiden U, Heurich M, 2017. Canopy foliar nitrogen retrieved from airborne hyperspectral imagery by correcting for canopy structure effects. International Journal of Applied Earth Observation and Geoinformation. 54: 84-94.

Wójtowicz M, Wójtowicz A, Piekarczyk J, 2016. Application of remote sensing methods in agriculture. Communications in Biometry and Crop Science. 11: 31-50.

Wright AF, Bailey JS, 2001. Organic carbon, total carbon, and total nitrogen determinations in soils of variable calcium carbonate contents using a Leco CN-2000 dry combustion analyzer. Communications in Soil Science and Plant Analysis. 32(19-20): 3243-3258.

Wu C, Niu Z, Tang Q, Huang W, 2008. Estimating chlorophyll content from hyperspectral vegetation indices: Modeling and validation. Agricultural and Forest Meteorology. 148(8): 1230-1241.

Zhang HK, Roy DP, Yan L, Li Z, Huang H, Vermote E, 2018. Characterization of Sentinel-2A and Landsat-8 top of atmosphere, surface, and nadir BRDF adjusted reflectance and NDVI differences. Remote Sensing of Environment. 215: 482-494.

Zhao G, Maclean LA, 2000. A comparison of canonical discriminant analysis and principal component analysis for spectral transformation. Photogrammetric Engineering and Remote Sensing. 66: 841-847. 